Development of a Continuous Bathymetric/Topographic Unstructured Coastal Flooding Model to Study Sea Level Rise in North Carolina

Jesse Feyen, Kurt Hess, Emily Spargo, Adeline Wong, Stephen White, Jon Sellars, and Stephen Gill

In Press

$9^{\text {th }}$ International Conference on Estuarine and Coastal Modeling Charleston, South Carolina October 31, 2005

Proceedings of the $9^{\text {th }}$ International Conference on Estuarine and Coastal Modeling, M. Spaulding et al., eds., ASCE. 


\title{
Development of a Continuous Bathymetric/Topographic Unstructured Coastal Flooding Model to Study Sea Level Rise in North Carolina
}

\author{
Jesse Feyen ${ }^{1}$, Kurt Hess ${ }^{2}$, Emily Spargo ${ }^{2}$, Adeline Wong ${ }^{2}$, Stephen White ${ }^{3}$, Jon \\ Sellars ${ }^{3}$, and Stephen Gill ${ }^{4}$
}

\begin{abstract}
A model to examine the impacts of long term sea level rise (SLR) is being implemented in the coastal North Carolina ecosystem. This area is particularly vulnerable to SLR, as a fragile system of barrier islands protects an extensive but sensitive estuarine system. The primary impact of SLR is to the hydrodynamic response of the system: circulation, tidal amplitude, and inundation patterns due to tides, winds, and storms can all change in response to rising sea level. Rates of SLR in the region are just under $3 \mathrm{~mm} /$ year and are increasing, and inundation is tied to inlet conveyance which can be modified by SLR.

A Coastal Flooding Model (CFM) has been developed for the region by combining a finite element hydrodynamic model with a continuous bathymetric and topographic elevation dataset. The CFM domain extends from $90 \mathrm{~km}$ offshore of the Outer Banks to the $15 \mathrm{~m}$ topographic contour and from northern Currituck Sound south to the New River. The CFM provides high resolution of coastal features down to $20 \mathrm{~m}$. High resolution topographic elevation data relative to the North American Vertical Datum of 1988 (NAVD 88) was combined with bathymetric sounding data relative to local tidal datums by transforming the tidal datums to NAVD 88 with the VDatum vertical transformation tool developed by the National Oceanic and Atmospheric Administration's (NOAA) National Ocean Service (NOS). The VDatum tool allows for transformation among nearly 30 different tidal, orthometric, and ellipsoidal vertical datums. A $6 \mathrm{~m}$ horizontal resolution continuous bathymetric/topographic (bathy/topo) Digital Elevation Model (DEM) was constructed for accurate modeling of inundation. The CFM is relative to the NAVD 88 vertical datum and was populated with DEM elevations where available and other topographic and bathymetric data relative to NAVD 88 elsewhere to create a continuous bathy/topo elevation field.

A two-dimensional barotropic model is used to simulate the tidal response in the CFM to study changes due to SLR and will also be used to model regional synoptic wind events and hurricane storm surge propagation with SLR. Accurate

\footnotetext{
${ }^{1}$ National Oceanic and Atmospheric Administration, National Ocean Service, Coast Survey Development Laboratory, Marine Modeling and Analysis Programs, N/CS13, 1315 EastWest Highway, Silver Spring, Maryland 20910; phone (301)-713-2809

${ }^{2}$ NOAA/NOS/Coast Survey Development Laboratory

${ }^{3}$ NOAA/NOS/National Geodetic Survey, Remote Sensing Division

${ }^{4}$ NOAA/NOS/Center for Operational Oceanographic Products and Services
} 
simulation of inundation patterns is accomplished by high localized resolution in the coastal zone, continuous bathy/topo data, and an accurate wetting/drying algorithm. The CFM is validated against observational data before modification of initial and boundary water levels to represent eustatic SLR. The RMS error at tidal stations was calculated for the primary constituent amplitudes and phases. The average of these RMS amplitude errors is $7.8 \times 10^{-3} \mathrm{~m}$ and the average of the RMS phase errors is $6.57^{\circ}$. Shoreline migration can be dynamically computed from the CFM simulation output as a function of SLR. Finally, the CFM will be coupled to submodels that characterize the ecological impact of SLR.

\section{Introduction}

SLR is a significant coastal stressor that threatens coastal ocean ecosystems, including both natural resources and societal uses. Communities built in the coastal zone are growing and becoming more susceptible to damage from coastal hazards, including SLR (Crossett et al. 2004). Similarly, valuable habitats such as oyster reefs, saltwater and brackish marshes, coastal forests, and submerged aquatic vegetation (SAV) beds occupy limited vertical and horizontal positions in the coastal environment and may be modified significantly by SLR. Rates of SLR are increasing and will continue to do so, as reported by the Intergovernmental Panel on Climate Change (Church et al. 2001). Conversely, management efforts to protect coastal assets for boating, beachfront access, private developments, and commercial interests cause shoreline hardening which impacts the local ecosystem. As sea level rises, the threat to coastal resources increases as does the pressure to modify the shore zone, increasing the impact humans have on the environment. Therefore it is important to understand how SLR threatens coastal resources and what impacts management decisions will have on the system.

These factors are particularly acute for North Carolina, which is characterized by a fragile barrier island system that protects a series of nearly non-tidal sounds. The United State Geological Survey (USGS) has classified much of North Carolina at very high risk due to SLR (Thieler and Hammar-Klose 1999). NOS analyses show that SLR in North Carolina averages $2.74 \mathrm{~mm}$ /year and that the tidal range is directly tied to inlet conveyance which could be modified by SLR (Zervas 2004). The land surrounding the Albemarle and Pamlico sounds is low lying: nearly $6,000 \mathrm{~km}^{2}$ of the North Carolina coast is from 0.0 to $1.5 \mathrm{~m}$ above mean sea level (Titus and Richman 2001), making it vulnerable to inundation by increased water levels. Modifications near the shore, such as elevated roadbeds and erosion control structures, may inhibit the natural landward ecosystem migration that occurs with SLR.

Local experts were consulted to elicit views on the environmental conditions that are considered to be sensitive to SLR in North Carolina. A workshop organized by NOAA's Center for Sponsored Coastal Ocean Research, Coastal Ocean Program (CSCOR/COP) on the ecological effects of SLR in North Carolina identified the primary impact of SLR as being physical change to the environment (NOAA CSCOR 2004). Circulation patterns, tidal amplitudes, and inundation due to tides, winds, and storms could all change in response to rising sea level. Shoreline is strongly affected by water levels, wave heights, and severe weather events. All of these factors are 
involved in determining the health and productivity of the estuarine system. Additionally, the Albemarle-Pamlico sound system (Figure 1) has limited connection to the outside ocean and therefore synoptic wind events are the dominant flooding mechanism in the system. A rise in sea level could increase the tidal response in the sounds and inundation during the wind events. These changes to the hydrodynamic conditions within the North Carolina ecosystem will have major impacts on many other processes. For example, oyster reefs, benthic habitat, SAV, and marsh platforms are all extremely sensitive to the hydrologic conditions. Sediment transport patterns play a crucial role in environmental conditions but are themselves primarily determined by waves and currents. Without a good understanding of these changes, it is difficult for coastal managers to develop plans to mitigate the effects of SLR.

\section{VDatum}

In order for models to accurately simulate inundation processes, it is important to combine data relative to several vertical datums. Previously, research of processes that take place across the land/water interface had at best an estimate of the adjustments necessary to match data relative to local tidal datums with data relative to orthometric (i.e., global sea level realizations developed through survey techniques) and ellipsoidal (i.e., three-dimensional, GPS-relative, mathematically defined) datums. Hydrodynamic models are generally populated by bathymetric data that is relative to local tidal datums. However, extending these models to overland regions to simulate inundation processes requires combining bathymetry with topography which is relative to different datums. Traditionally, models have been restricted to applying estimates of how the relationships between local (tidal) and global datums have varied across the model domain. However, these estimates are often overly simplistic as the relationship between different datums varies spatially throughout a domain. For example, the distance between Mean Lower Low Water (MLLW) and NAVD 88 can vary according to the shallow water hydrodynamic response. Therefore it is necessary to provide a systematic methodology to define vertical datum transformations in the coastal zone that accounts for these variations.

The VDatum vertical transformation tool has been developed by NOAA's National Ocean Service (NOS) to provide a methodology for combining data from a range of datums (Milbert 2002, Parker 2002, Parker et al. 2003). VDatum is being developed on a regional basis for the U.S. coastline by NOS' Coast Survey Development Laboratory (CSDL), National Geodetic Survey (NGS), and Center for Operational Oceanographic Products and Services (CO-OPS). A version covering the North Carolina Outer Banks and Albemarle-Pamlico sound system has been developed (Hess et al. 2004, Hess et al. 2005) and is available at the VDatum web page: http://nauticalcharts.noaa.gov/csdl/vdatum.htm. This VDatum application in North Carolina provides the ability to adjust all geophysical data collected to a common vertical datum to support the study and modeling of processes across the land/water interface. This includes study of tidal and wind-driven inundation, storm surge, and sea level rise.

There are three main components of the North Carolina VDatum implementation. First, a hydrodynamic model was used to simulate tidal circulation 
over a one month period. This one month time period is sufficient for resolving the significant primary, compound, and overtides and for computing tidal datums. Long term seasonal variations in water level are excluded because they will average out over a yearly cycle and thus the datums will be more accurate without their influence on a shorter term record. Tidal datum fields were calculated from the modeled water level time series and validated against CO-OPS observed tidal datum stations. These tidal datum fields include spatial variations in the datums that result from nonlinear hydrodynamic effects. The Advanced Circulation (ADCIRC) computational model (Luettich et al. 1992) was used to solve the equations of conservation of mass and momentum in a depth-integrated barotropic mode, appropriate and used extensively for calculating water surface time histories driven by tidal forcing (e.g., Mukai et al. 2002). This is because the tidal signal is a barotropic process that does not lead to generation of significant variation in currents over the vertical. The exclusion of baroclinicity in this model application is appropriate because fresh water inflow is minimal and annual temperature fluctuations are averaged out of observed water level datums. The ADCIRC model employs an unstructured meshing strategy that is well suited for variable coastal geography. The computational mesh varies in resolution from tens of kilometers offshore to tens of meters at narrow inlet and channel locations in order to resolve variations in tidal wavelengths and currents according to geographic features. This strategy provides a cost effective model that minimizes computational points and generates approximately constant error across the domain. The VDatum hydrodynamic tidal domain shown in Figure 2 has 36,399 nodes and computes tidal response for the North Carolina sound system from the shelf-based open boundary to the Mean High Water (MHW) shoreline. In order to convert NOS' bathymetric depths from their native vertical tidal datums (e.g., Mean Low Water (MLW) and Mean Lower Low Water (MLLW)) to local Mean Sea Level (MSL), modeled tidal datums were generated iteratively and use to adjust bathymetry. First, NOS observed tidal datums were used to adjust bathymetry from its native datum to MSL. Second, the hydrodynamic model was run with the adjusted bathymetry to compute tidal datum fields. Then the computed tidal datums were used to readjust bathymetric data from its initial tidal datum (e.g., MLW) to MSL. This process continued iteratively until the adjustments of the bathymetric data to MSL converged in subsequent model runs (i.e., the MLW to MSL difference remained constant). The final tidal datums from the model do not match exactly with the NOS datums reported at water level stations located in the domain, primarily because the model runs reflect only tidal forcing and the datums reported by NOS include meteorological effects. A spatial interpolation of the error in the modeled datums was made to adjust the hydrodynamic model results to match the NOS data at the stations. The corrected tidal datum fields were interpolated onto a structured grid for use in VDatum. For information on the use of hydrodynamic models to generate tidal datum fields see Spargo et al. (these proceedings).

Second, NGS benchmark data at CO-OPS tidal station gauges was used to determine the relationship between local tidal datums (calculated from gauge records) and surveyed NGS benchmarks relative to NAVD 88. NGS creates a Topography of the Sea Surface (TSS) by spatially distributing the benchmark data across the 
VDatum region. The TSS is used by VDatum to define the conversion from local tidal datums to NAVD 88.

Third, VDatum utilizes a NGS geoid model that provides the relationship between orthometric (e.g., NAVD 88) and ellipsoidal (e.g., the North American Datum of 1983 (1986)) datums. This model is based upon gravimetric data that describes the Earth's geoid across the continental U.S. and provides the link between NAVD 88 and the three dimensional ellipsoidal datums that are available in the VDatum software package.

\section{Digital Elevation Model}

A high resolution digital elevation model (DEM) was constructed by NGS for the western Pamlico Sound portion of North Carolina (White and Sellars 2004). This is the focused study area where the DEM will be combined with hydrodynamic and ecological models to predict the impact of SLR on the ecosystem. The DEM utilizes high resolution Federal Emergency Management Agency (FEMA) Light Detection and Ranging (LIDAR) elevation data for topographic information where available and NOAA soundings for bathymetric information in order to produce a DEM with 6 $\mathrm{m}$ resolution in the horizontal direction. Any small gaps in topography data were filled by other sources such as the USGS National Elevation Dataset (NED). Vertical accuracy depends on the source data (e.g., 0.20 to $0.25 \mathrm{~m}$ where FEMA LIDAR data is utilized, $0.30 \mathrm{~m}$ for hydrographic soundings in less than $20 \mathrm{~m}$ of water). The bathymetric data comes from NOS hydrographic soundings that have taken place over the past century and a half. Over that time vertical datum standards have changed, and therefore source data is referenced to MLW, MLLW, and the Low Water Datum (LWD; in non-tidal portions of the sound). Using the tidal datum fields generated by the VDatum hydrodynamic model, these bathymetric data were adjusted to MSL and then converted to NAVD 88. These bathymetric data were then combined with topographic data to create a continuous bathy/topo dataset. The final DEM covers the area shown in Figure 3, including Bogue, Back, Core, and western Pamlico sounds, the Neuse River, and the corresponding coastal shelf areas, barrier islands, and overland regions.

\section{Coastal Flooding Model}

Accurate understanding of hydrodynamic conditions significantly impacts the ability to predict the effects of SLR. To this end, CSDL has developed a predictive hydrodynamic model of North Carolina's coastal areas that integrates the VDatum products in a combined modeling process. Using the DEM as well as USGS elevation data, CSDL has integrated land areas with the VDatum hydrodynamic tidal model to produce a Coastal Flooding Model (CFM). This model is able to simulate not only tidal response but also wind-driven (including hurricane) circulation within the system as well as changes in shoreline and inundation patterns. The purpose of the CFM is to study how SLR will affect the coastal ecosystem, and the CFM is unique because it treats the landward and seaward areas as a single, continuous environment. 
The development of the CFM required the generation of a specialized, high resolution computational grid. The grid for the existing VDatum tidal model extends from north of Currituck Sound southward to the New River and from the heads of major rivers seaward to approximately $90 \mathrm{~km}$ offshore from the barrier island chain, as shown in Figure 2. However, this model does not include any overland areas, and all bathymetric depths are relative to mean sea level. By contrast, the CFM requires the addition of land areas, and continuous contours of bathymetric and topographic data relative to a single non-tidal datum (i.e., NAVD 88). A $15 \mathrm{~m}$ topographic contour (relative to NAVD 88) was generated from the $30 \mathrm{~m}$ horizontal resolution USGS NED and used as the landward boundary. Computational mesh has been added between the prior shoreline and this land boundary, including all island areas, as shown in Figure 4. The $15 \mathrm{~m}$ contour was chosen since this will allow the CFM to model severe storm surge conditions. The model incorporates the full AlbemarlePamlico sound system in order to accurately model circulation throughout the system. Resolution ranges from $5 \mathrm{~km}$ offshore down to $20 \mathrm{~m}$ within narrow channels such as the Intracoastal Waterway. Resolution of inlets is generally from 100 to $200 \mathrm{~m}$, with more than 10 elements across these inlets. Mesh size within sounds ranges between several hundred meters to nearly two kilometers, and rivers are discretized ranging from many nodes across to a pair of elements only $50 \mathrm{~m}$ in size. The goals in developing the mesh were to provide numerous computational points across important inlets and within waterways, and to align the mesh with shoreline and bathymetric and topographic contours. This was accomplished by varying resolution according to the scale of each feature. The mesh was compared to NOAA charts and USGS quadrangle maps in digital form which can be loaded in GeoTIFF format into the mesh generation program SMS (Surface-water Modeling System).

The CFM grid was populated by depths and elevations in a consistent vertical datum (NAVD 88). In order to produce accurate predictions of SLR, it is necessary to have accurate and continuous vertical (bathymetric and topographic) information. The VDatum software was used to transform bathymetric sounding data from tidal datums (e.g., relative to MLW or MLLW) to the same orthometric datum (NAVD 88) used for topographic data. CFM elevations are derived directly from the DEM where it provides coverage. The DEM does not cover all of the CFM mesh, however; it is limited to the ecological study area that ranges from southwest of the White Oak River to northeast of Hatteras Inlet, as shown in Figure 3. In area the DEM does not cover, NOS sounding data was used for bathymetric depths and the USGS NED for topographic heights. All bathymetric and topographic data are applied to the computational mesh by interpolating at the local mesh scale. This was done by averaging all data points within the cluster of elements surrounding each node. Details of the mesh and topo/bathy elevation around Beaufort Inlet are shown in Figure 5.

Although there are several computational models that use unstructured grid techniques, the finite element model ADCIRC is used because of its computational efficiency, ability to model inundation, and validation as a storm surge model. In ADCIRC, the solution of the shallow water equations (SWE) allows a description of the hydrodynamic circulation in the system. The finite element discretization of the SWE allows computation of the conservation of mass and momentum in the system 
to determine the water surface elevation and depth-averaged horizontal velocity. The ADCIRC model has features that are key to modeling the effects of SLR for a variety of conditions. First, it has an effective wetting and drying methodology that allows wave propagation and retreat over land. This is necessary to determine changes in tidal inundation and shoreline as sea level rises, and to accurately model synoptic wind event inundation and hurricane storm surge propagation. Second, it is a computationally efficient model that uses parallel processing technology. Finally, the unstructured grid approach is very capable of representing complex coastlines and hydrodynamic features. Details describing the numerical methodology are discussed in the ADCIRC theory report (Luettich and Westerink 2004). It has been widely used, including studies such as the generation of basin-scale tidal databases (Mukai et al. 2002), modeling of estuarine-scale circulation (Luettich et al. 1998, Hench and Luettich 2003), prediction of hurricane storm surge (Blain et al. 1994), and examination of ecological processes in estuaries (Luettich et al. 1999).

\section{Model Validation and Application}

Tidal validation of the regional scale CFM with NOS tidal harmonic constants and datums at stations throughout North Carolina is underway. Boundary condition forcing was specified by harmonic constants for 38 tidal constituents from a U.S. East Coast inverse modeled tidal database (Myers unpublished, Myers and Baptista 2001). The ADCIRC model utilized an eddy viscosity coefficient of $2.0 \mathrm{~m}^{2} / \mathrm{s}$. The use of a spatially constant horizontal eddy viscosity has been extensive in the ADCIRC model with much success. It is appropriate since its low value minimizes non-physical momentum diffusion/dispersion and the unstructured grid resolves the predominant features of the flow except in turbulent shoreline regions. A hybrid quadratic friction formulation was specified which applies a traditional quadratic function with a nondimensional friction coefficient of 0.0025 in water deeper than $0.5 \mathrm{~m}$ while increasing the friction coefficient exponentially in water shallower than $0.5 \mathrm{~m}$, representing the increased friction during overland inundation. The model was run for 40 days with an 8 day hyperbolic tangent ramping function and a 2 second time step. Model output was harmonically analyzed at NOS tidal constituent stations for the 23 constituents that can be extracted from a 32 day record. Figure 6 shows tidal constituent station locations, which are distributed evenly among tidal (observed tide range close to $1 \mathrm{~m}$ ) and nearly non-tidal (observed tide range close to $0.25 \mathrm{~m}$ ) areas. The RMS error at each station was calculated for the $\mathrm{M}_{2}, \mathrm{~N}_{2}, \mathrm{~S}_{2}, \mathrm{~K}_{1}$, and $\mathrm{O}_{1}$ constituent amplitudes and phases. The average of these stations' RMS amplitude errors is $7.8 \times 10^{-3} \mathrm{~m}$ and RMS phase errors is $6.57^{\circ}$; the errors at each station are shown in Table 1. The phasing errors were not biased to leading or lagging except within the Back-Core Sound system where significant phase leading exists in the model results, which is shown in the error at the Sea Level, Core Sound station. Tidal datums were calculated by examining the 32 day water level time series at 44 NOS tidal datum stations shown in Figure 7. Observed tidal range (MHW-MLW) at these stations varies from just over $1 \mathrm{~m}$ outside the barrier islands to less than $0.05 \mathrm{~m}$ inside the sounds away from the tidal inlets. The modeled tidal range was computed at each of these stations and compared to the reported range to determine an average error of 
$0.0709 \mathrm{~m}$ on an average range of $0.62 \mathrm{~m}$. A distribution of error values in the modeled tidal range is shown in Figure 7. The spatial distribution of error does not indicate a bias for error size or overprediction versus underprediction as a function of tide range. This is likely because the observation stations are both temporally and spatially well distributed, leading to a range in sampling periods and quality.

Table 1. RMS error at NOS stations for the $\mathrm{M}_{2}, \mathrm{~N}_{2}, \mathrm{~S}_{2}, \mathrm{~K}_{1}$, and $\mathrm{O}_{1}$ tidal constituents.

\begin{tabular}{llll}
\hline Name & ID Number & Amplitude Error (m) & Phase Error ( ${ }^{\mathbf{0}}$ \\
\hline Duck FRF Pier & 8651370 & $1.009 \times 10^{-2}$ & 6.505 \\
\hline Oregon Inlet Marina & 8652587 & $7.519 \times 10^{-3}$ & 2.003 \\
\hline Cape Hatteras Fishing Pier & 8654400 & $7.010 \times 10^{-3}$ & 4.399 \\
\hline Ocracoke Island & 8654792 & $1.093 \times 10^{-2}$ & 8.912 \\
\hline Sea Level, Core Sound & 8655875 & $2.638 \times 10^{-3}$ & 29.996 \\
\hline Beaufort Duke Marine Lab & 8656483 & $9.232 \times 10^{-3}$ & 3.448 \\
\hline Morehead City Harbor & 8656502 & $7.235 \times 10^{-3}$ & 4.066 \\
\hline
\end{tabular}

Preliminary tests of the CFM model have been performed by extracting a local area grid of the Newport River basin. This local model allows for extensive testing of the model capability and parameters as well as mesh resolution requirements. Tidal boundary conditions were applied where the Newport River meets Bogue and Back Sounds. Model stability sensitivity to input parameters such as time step, bottom friction, lateral eddy viscosity, and spatial resolution were tested in order to ensure model stability without resorting to excessive diffusion via input parameters. Modeled shorelines (including change due to SLR) were computed by determining the intersection of modeled tidal datum fields (e.g., MHW) with bathy/topo contours. Figure 8 shows the Newport River computed MHW shorelines for both current sea level and a $0.30 \mathrm{~m}$ offshore rise in sea level along with the boundary of the local area test grid. These shorelines were determined by using the hydrodynamic model to compute month-long tidal records to generate tidal datum fields. The datums can then either be mapped to the computational mesh or high resolution datasets such as the DEM. It is only possible to compute tidal datums at computation points that have a continuous water level record; this means nodes in the intertidal zone that dry cannot be used. While datums can only be calculated at non-drying nodes, they are extrapolated landward so that they are distributed across the domain. This allows computation of tidal datum shorelines such as the MHW shoreline by finding where the MHW datum intersects bathymetric and topographic contours. The shoreline change shown in Figure 8 is indicative of the results from this methodology, which translates eustatic SLR to hydrodynamic change. Areas dominated by low-lying topography are shown to be very vulnerable to SLR. For example, the western upstream end of the Newport River shows a change in shoreline position on the order of several kilometers due to the inundation of an extensive marsh system.

The use of a hydrodynamic model to compute tidal datum shoreline changes is an improvement from the commonly used approach of using a constant adjustment (e.g., the $1.0 \mathrm{~m}$ topographic contour) to indicate areas inundated by SLR. Computation of shoreline from computational model output includes variations in water levels due to nonlinear hydrodynamic effects. The nonlinear continuity, 
advection, and friction processes generate a residual component of the tidal signal that modifies tidal datums (Prandle 1990, Parker 1990). These nonlinear terms are of significance in estuaries and embayments to due the shallow, decreasing bathymetry and converging geometry at inlets and river mouths. They produce variations in tidal response from the nearly linear offshore signal due to the generation of an asymmetric tidal cycle. As sea level rises the geographic conditions that influence these local nonlinear responses change because of the rise in water level and increasing water depth. This alters conditions at inlets, barrier islands, and the shore, causing changes in tidal datum shorelines that cannot be represented by a constant vertical increase in shoreline position. Note that the use of a physical model incorporating nonlinear hydrodynamics and a continuous elevation dataset still excludes geological and ecological response to SLR such as subsidence, sediment transport, and marsh accretion. These processes will begin to be addressed by coupling this physical model with ecological models that can provide feedback describing these changes.

\section{Future Work}

With completion of tidal validation of the CFM, the effect of SLR on hydrodynamic processes can be studied for the NC sound system. First, changes in tidal harmonic constants will be calculated under the effect of SLR. Second, changes in tidal datum shorelines will be calculated throughout the study area as demonstrated for the local test region. Third, the impact of synoptic wind events will be examined by forcing the CFM with wind fields and validating with water level records. This is an important process in the North Carolina sounds since much of the system is non-tidal and the primary inundation events are wind-driven, such as northeasters. The range and extent of inundation will be impacted by SLR, which can be shown by model output. Fourth, the CFM can be utilized to study hurricane storm surge flooding of the NC system and the significance of changes in flooding with SLR.

The development of the CFM has been to support the NCCOS/COP study of the ecological effects of SLR. Using the CFM to study changes in inundation with SLR is not complete without including ecological processes, including geomorphological change; erosion and deposition; marsh accretion, growth, and migration; productivity of oyster reef, SAV, and benthic habitats; and anthropomorphic change. Therefore, the CFM can be used to drive a suite of ecological submodels of these processes. These submodels and the CFM can provide iterative updates to each other to generate an overall prediction of the ecological effects of SLR. Included in these ecological submodels are the impacts of anthropomorphic changes such as shoreline hardening in response to SLR. This combined modeling process can provide coastal managers with key modeling and mapping tools to assess the risk of SLR to the NC coastal environment. The long term goal is to use the methodology developed over the course of this project as a tool for NOAA and coastal managers to examine the long-term impacts of SLR for coastal ecosystems throughout the United States. This can be accomplished by developing similar CFMs and coupling them with locally-relevant ecological submodels. 


\section{References}

Blain, C.A., J.J. Westerink and R.A. Luettich. (1994). "The influence of domain size on the response characteristics of a hurricane storm surge model." J. Geophys. Res., 99(C9), 18467-18479.

Church, J.A., J.M. Gregory, P. Huybrechts, M. Kuhn, K. Lambeck, M.T. Nhuan, D. Qin, and P.L. Woodworth. (2001). "Changes in sea level." Climate change 2001: the scientific basis. Contribution of working group I to the third assessment report of the intergovernmental panel on climate change, Houghton, J.T., Y. Ding, D.J. Griggs, M. Noguer, P.J. van der Linden, X. Dai, K. Maskell, and C.A. Johnson, eds.. Cambridge University Press, Cambridge, UK and New York.

Crossett, K.M., T.J. Culliton, P.C. Wiley, and T.R. Goodspeed. (2004). "Population trends along the coastal United States: 1980-2008." NOAA Coastal Trends Report Series, NOAA, Silver Spring, MD.

Hench, J. L. and R. A. Luettich, Jr. (2003). "Transient tidal circulation and momentum balances at a shallow inlet." J. Phys. Ocean., 33 (4), 913-932.

Hess, K.W., S.A. White, J. Sellars, E. Spargo, A. Wong, S.K. Gill, and C. Zervas. (2004). "North Carolina sea level rise project: interim technical report." NOAA Tech. Mem. NOS CS 5, National Ocean Service, NOAA, Silver Spring, MD.

Hess, K. W., E. Spargo, A. Wong, S. A. White, and S. K. Gill. (2005). "VDatum for central coastal North Carolina: tidal datums, marine grid, and sea surface topography." NOAA Tech. Rep. NOS CS 21, National Ocean Service, NOAA, Silver Spring, MD.

Luettich, Jr., R.A., J.L. Hench, C.D. Williams, B.O. Blanton, and F.E. Werner. (1998). "Tidal circulation and larval transport through a barrier island inlet." Esuarine and Coastal Modeling V, M. Spaulding et al., eds., ASCE, 849-863.

Luettich, Jr., R.A., J.L. Hench, C.W. Fulcher, F.E. Werner, B.O. Blanton and J.H. Churchill. (1999). "Barotropic tidal and wind driven larval transport in the vicinity of a barrier island inlet." Fish. Oceanog., 8(Suppl. 2), 190-209.

Luettich, Jr., R.A., and J.J. Westerink. (2004). "Formulation and numerical implementation of the 2D/3D ADCIRC finite element model version 44.XX." ADCIRC Theory Rep., http://www.marine.unc.edu/C_CATS/adcirc/adcirc_theory_ 2004_05_14.pdf $>$ (Jan. 26, 2005).

Luettich, Jr., R.A., J.J. Westerink, and N.W. Scheffner. (1992). “ADCIRC: an advanced three-dimensional circulation model for shelves, coasts and estuaries; report 1: theory and methodology of ADCIRC-2DDI and ADCIRC-3DL." Dredging 
Research Program Tech. Rep. DRP-92-6, U.S. Army Engineers Waterways Experiment Station, Vicksburg, MS.

Milbert, D.G. (2002). "Documentation for VDatum (and VDatum tutorial); vertical datum transformation software. Ver. 1.06." VDatum106, http//:nauticalcharts.noaa. gov/csdl/Vdatum_data/VDatum106.pdf $>$ (Oct. 5, 2005).

Mukai, A.Y., J.J. Westerink, R.A. Luettich Jr., and D. Mark. (2002). "Eastcoast 2001: a tidal constituent database for the western North Atlantic, Gulf of Mexico and Caribbean Sea." Coastal and Hydraulics Laboratory Tech. Rep. ERDC/CHL TR-0224, US Army Engineer Research and Development Center.

Myers, E.P. "Tidal datum inversion model of the east coast of the United States." Unpublished manuscript.

Myers, E.P. and A.M. Baptista. (2001). "Inversion for tides in the Eastern North Pacific Ocean." Adv. Water Res., 24, 505-519.

NOAA CSCOR. (2004). "Ecological effects of sea level rise." NOAA White Paper, http://www.cop.noaa.gov/products/multimedia/presentations/mt-2004-beau-cc/sea_ level_rise_wp.pdf $>($ Oct. 5, 2005).

Parker, B.B. (1990). "The relative importance of the various nonlinear mechanisms in a wide range of tidal interactions (review)." Tidal Hydrodynamics, B.B. Parker, ed., John Wiley \& Sons, New York, 237-268.

Parker, B.B. (2002). "The integration of bathymetry, topography, and shoreline, and the vertical datum transformations behind it." Int. Hydrogr. Rev., 3(3), 14-26.

Parker, B.B., K.W. Hess, D.G. Milbert, and S.K. Gill. (2003). "A national vertical datum transformation tool." Sea Tech., 44(9), 10-15.

Prandle, D. (1990). "Tides in estuaries and embayments (review)." Tidal Hydrodynamics, B.B. Parker, ed., John Wiley \& Sons, New York, 125-152.

Spargo, E., K. Hess, E. Myers, Z. Yang, and A. Wong. (these proceedings). "Tidal datum modeling in support of NOAA's vertical datum transformation tool." Estuarine and Coastal Modeling, Proc. of the Ninth Int. Conf., M.L. Spaulding et al., eds. ASCE.

Thieler, E.R., and E.S. Hammar-Klose. (1999). "National assessment of coastal vulnerability to sea-level rise; preliminary results for the U.S. Atlantic coast." U.S. Geological Survey Open-File Report 99-953, USGS, Reston, VA.

Titus, J.G. and C. Richman. (2001). "Maps of lands vulnerable to sea level rise." EPA Global Warming Resource Center Publications, http://yosemite.epa.gov/oar/global 
warming.nsf/content/ResourceCenterPublicationsSLRMapsIndex.html > (Jan. 25, 2005).

White, S.A. and J. Sellars. (2004). "Creation of the digital elevation model for the North Carolina sea level rise project." Unpublished report, National Geodetic Survey, NOAA, Silver Spring, MD.

Zervas, C. E. (2004). "North Carolina bathymetry/topography sea level rise project: determination of sea level trends." NOAA Tech. Rep. NOS CO-OPS 041, National Ocean Service, NOAA, Silver Spring, MD. 


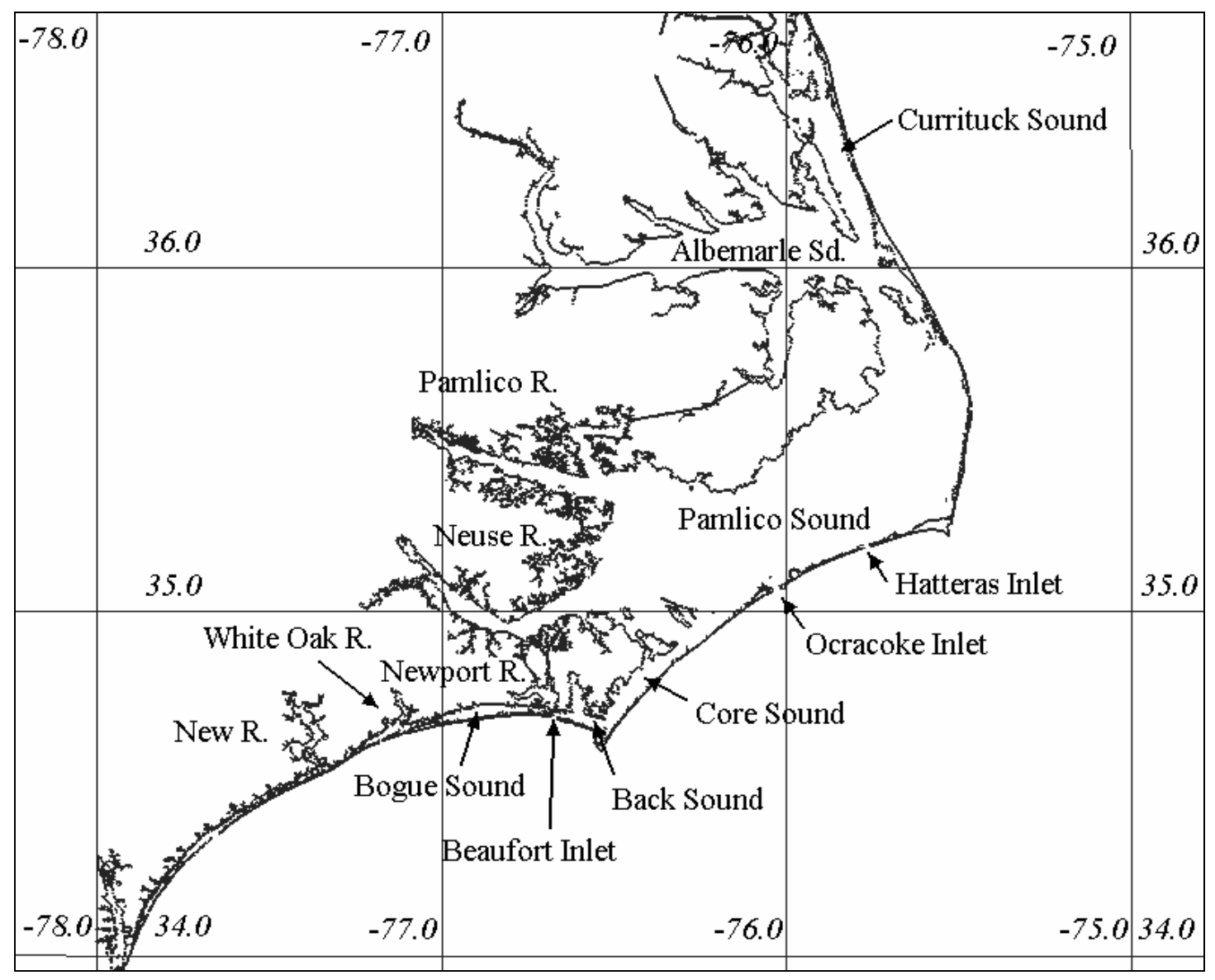

Figure 1. North Carolina Albemarle-Pamlico sound system. 


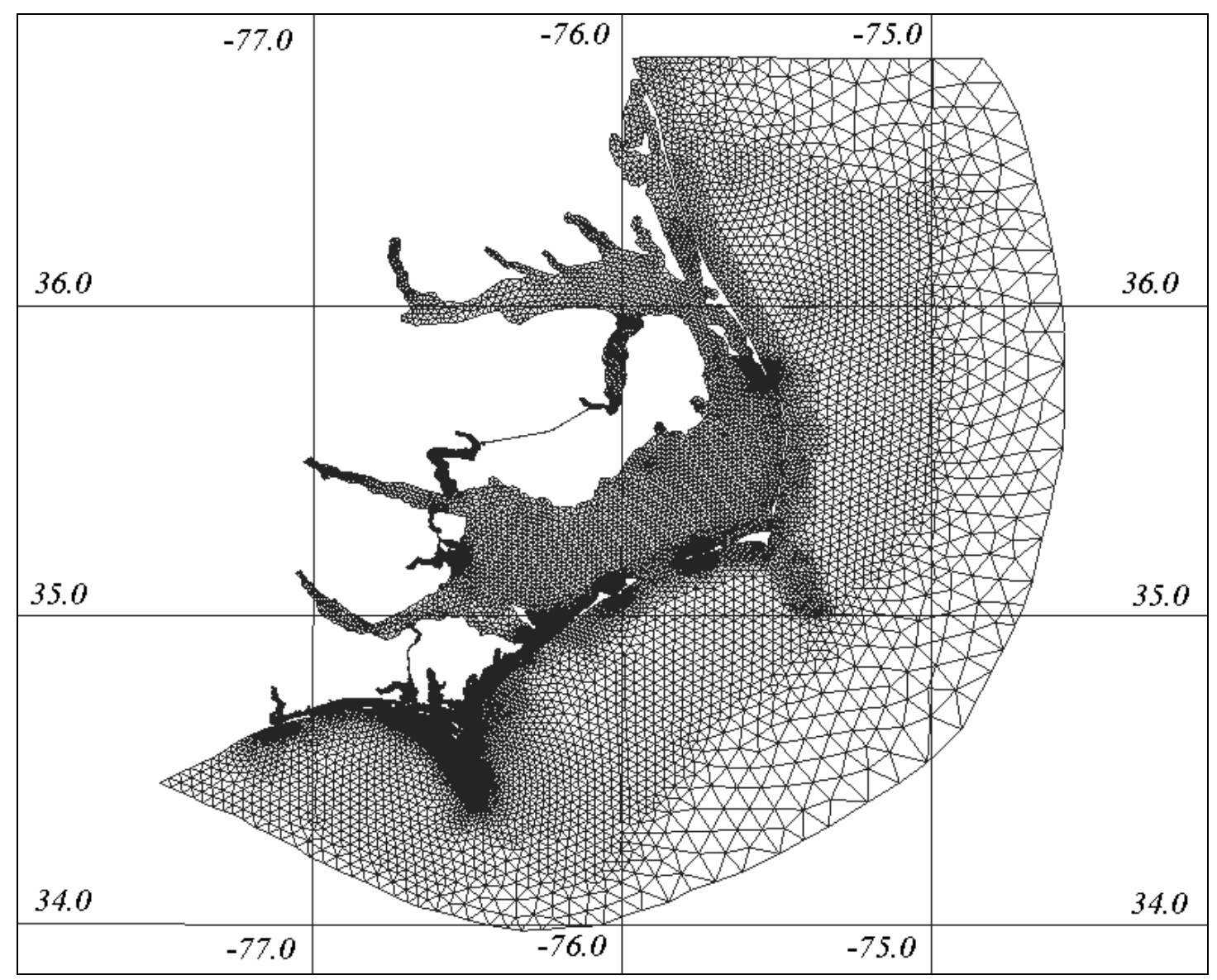

Figure 2. North Carolina VDatum tidal hydrodynamic model grid. 


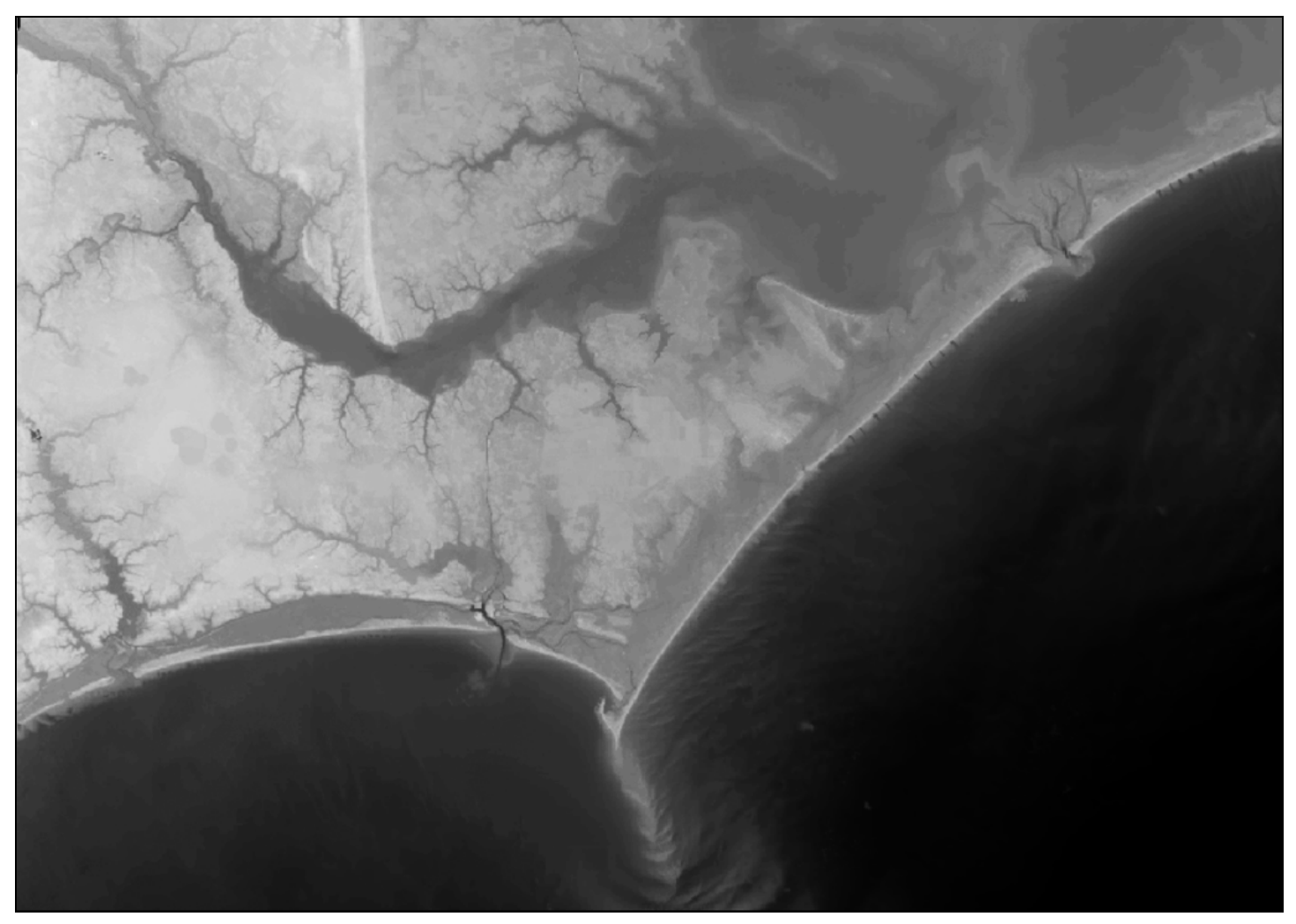

Figure 3. Digital Elevation Model. 


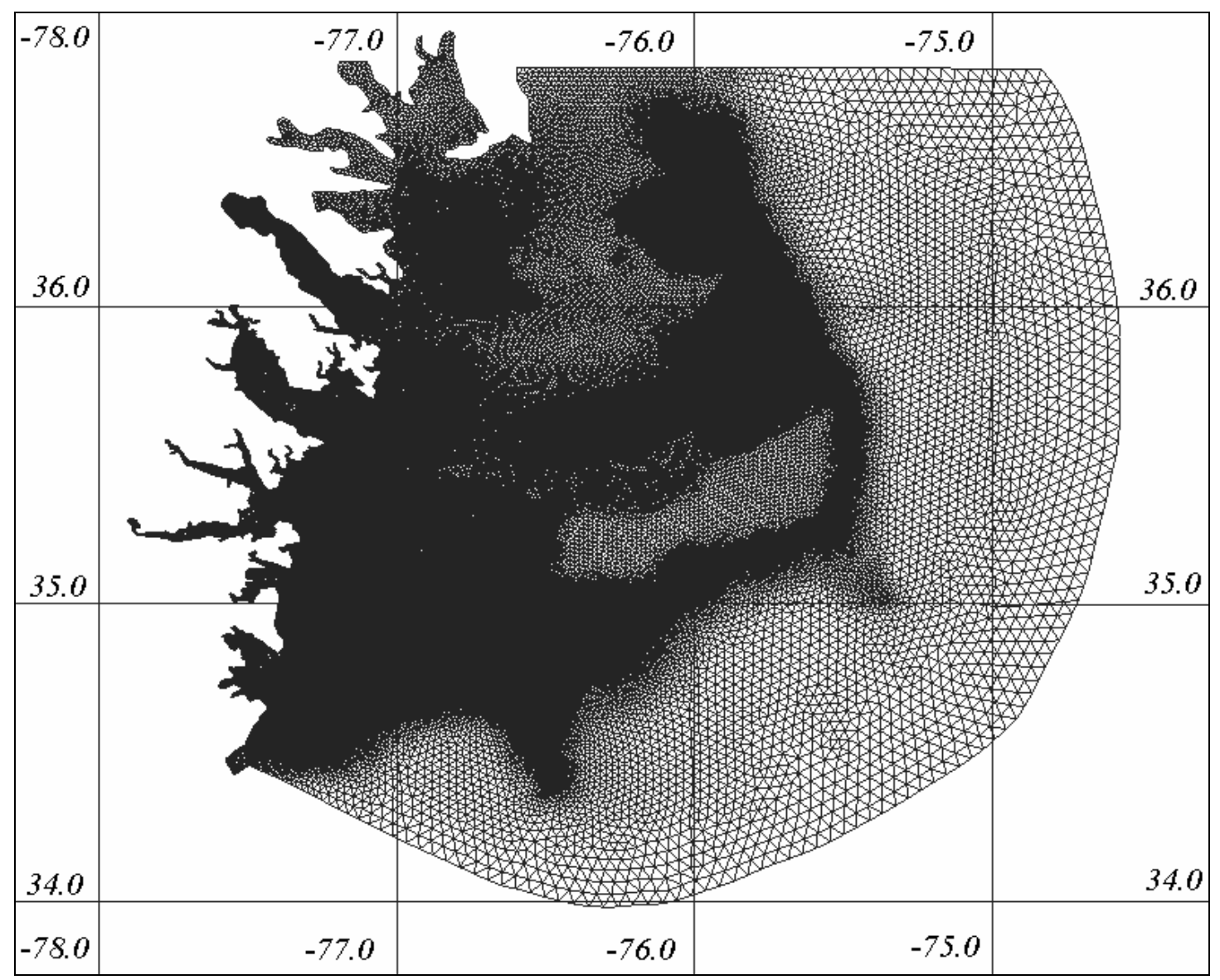

Figure 4. Coastal Flooding Model grid for North Carolina. 


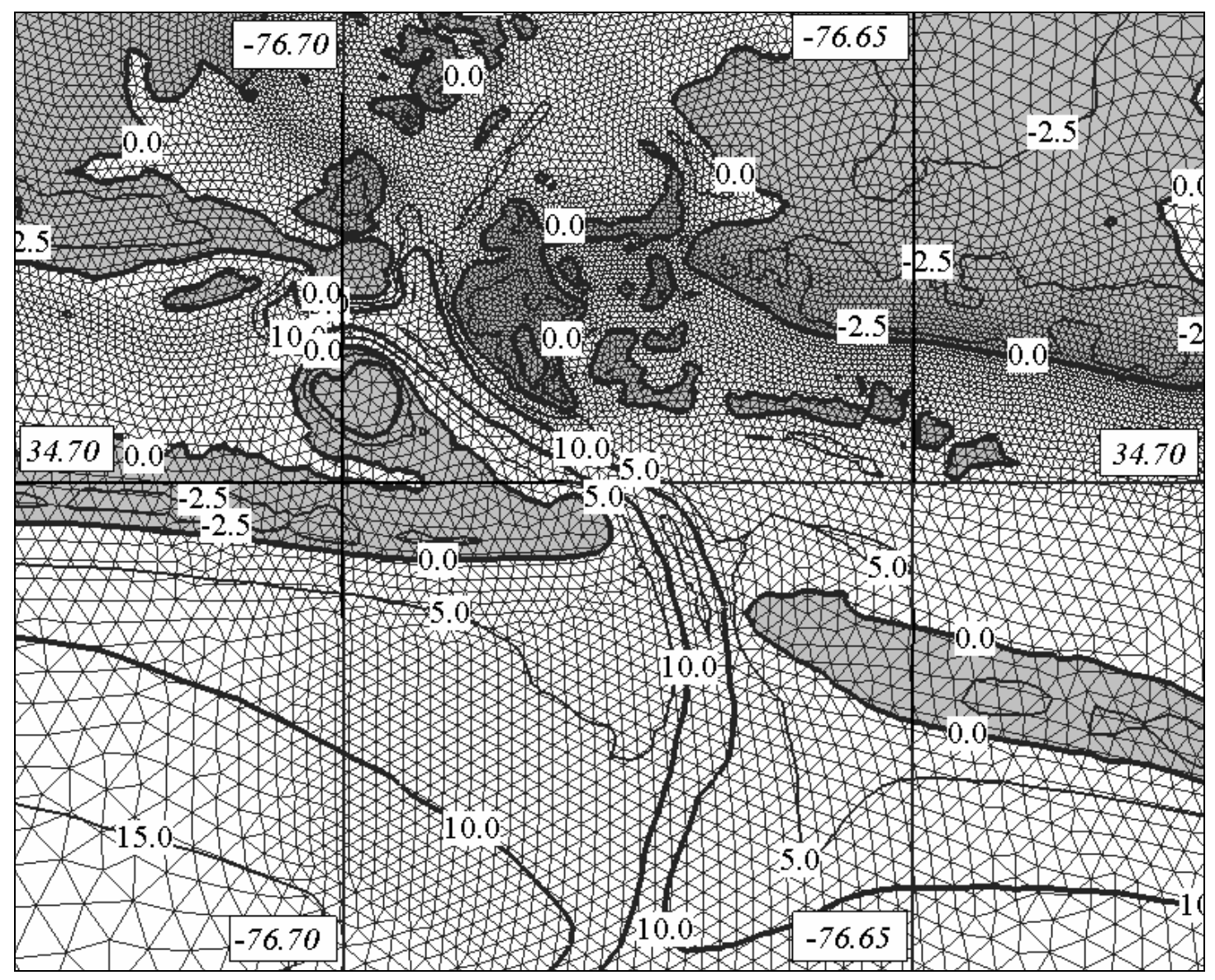

Figure 5. Coastal Flooding Model grid and topography/bathymetry at Beaufort Inlet, $\mathrm{NC}$ with areas above the datum shaded to approximate topographic coverage (m NAVD 88, with positive values indicating depth below the datum). 


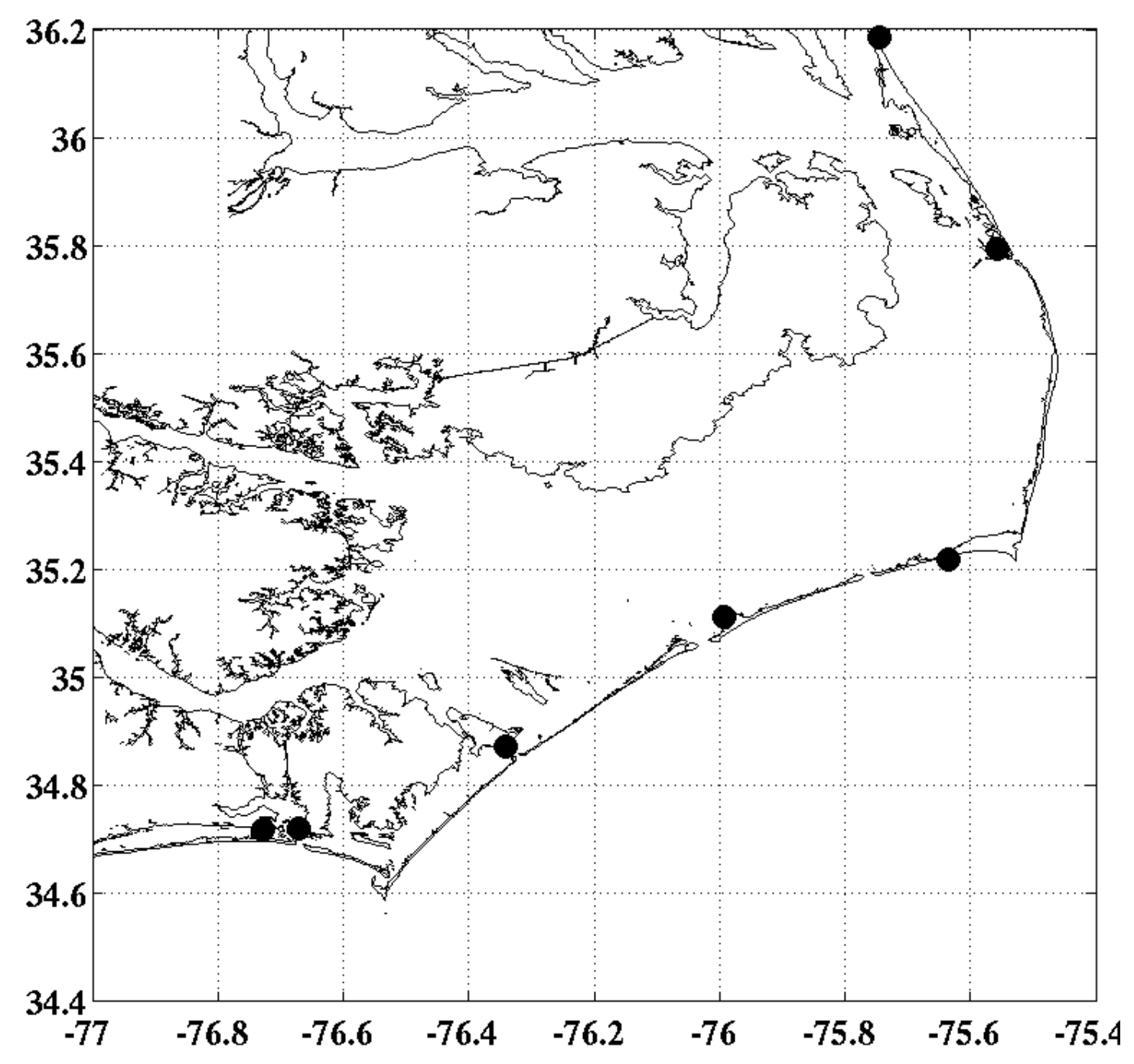

Figure 6. NOS tidal harmonic constant stations. 


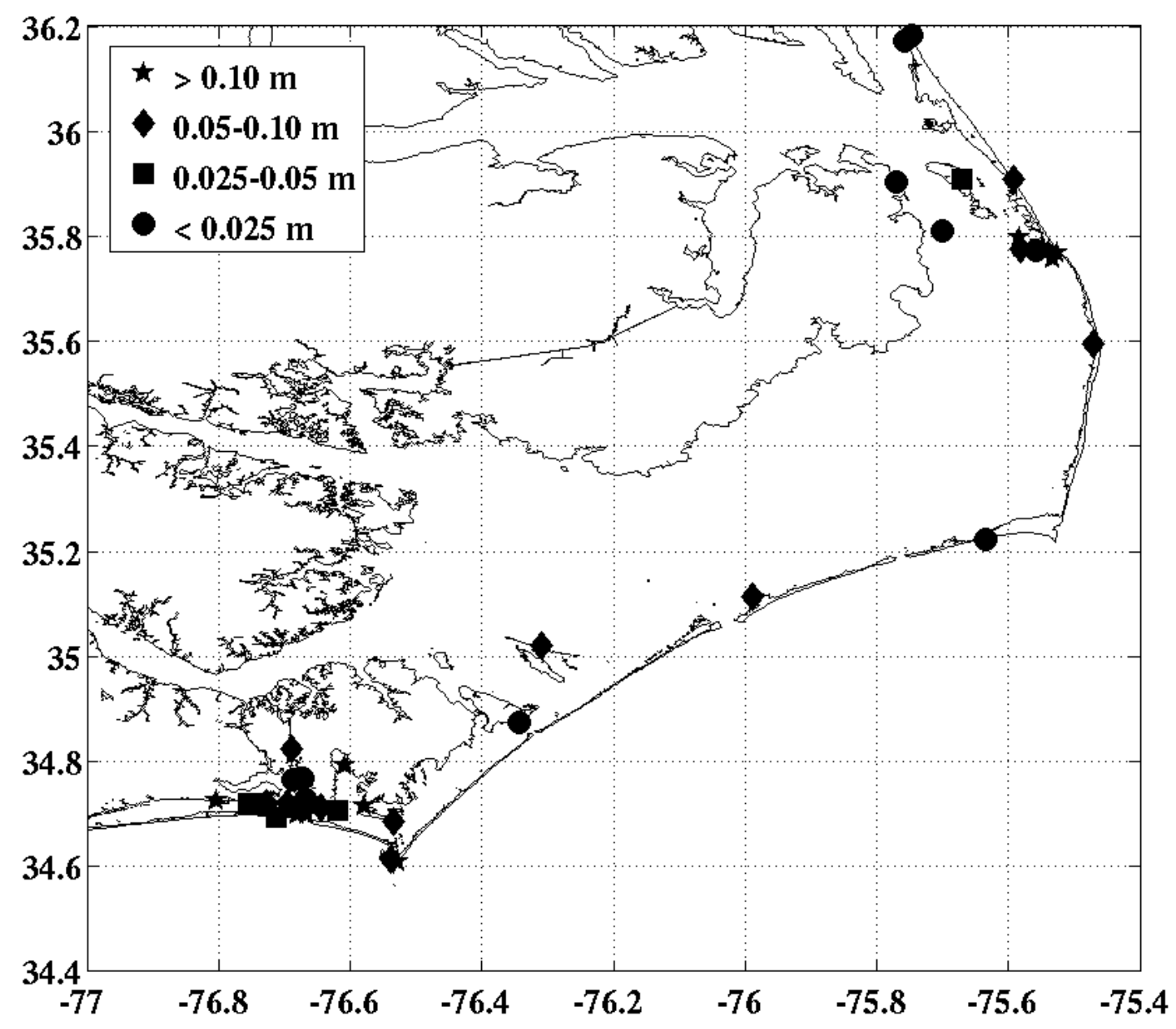

Figure 7. Error in tidal range at 44 NOS tidal datum stations. 


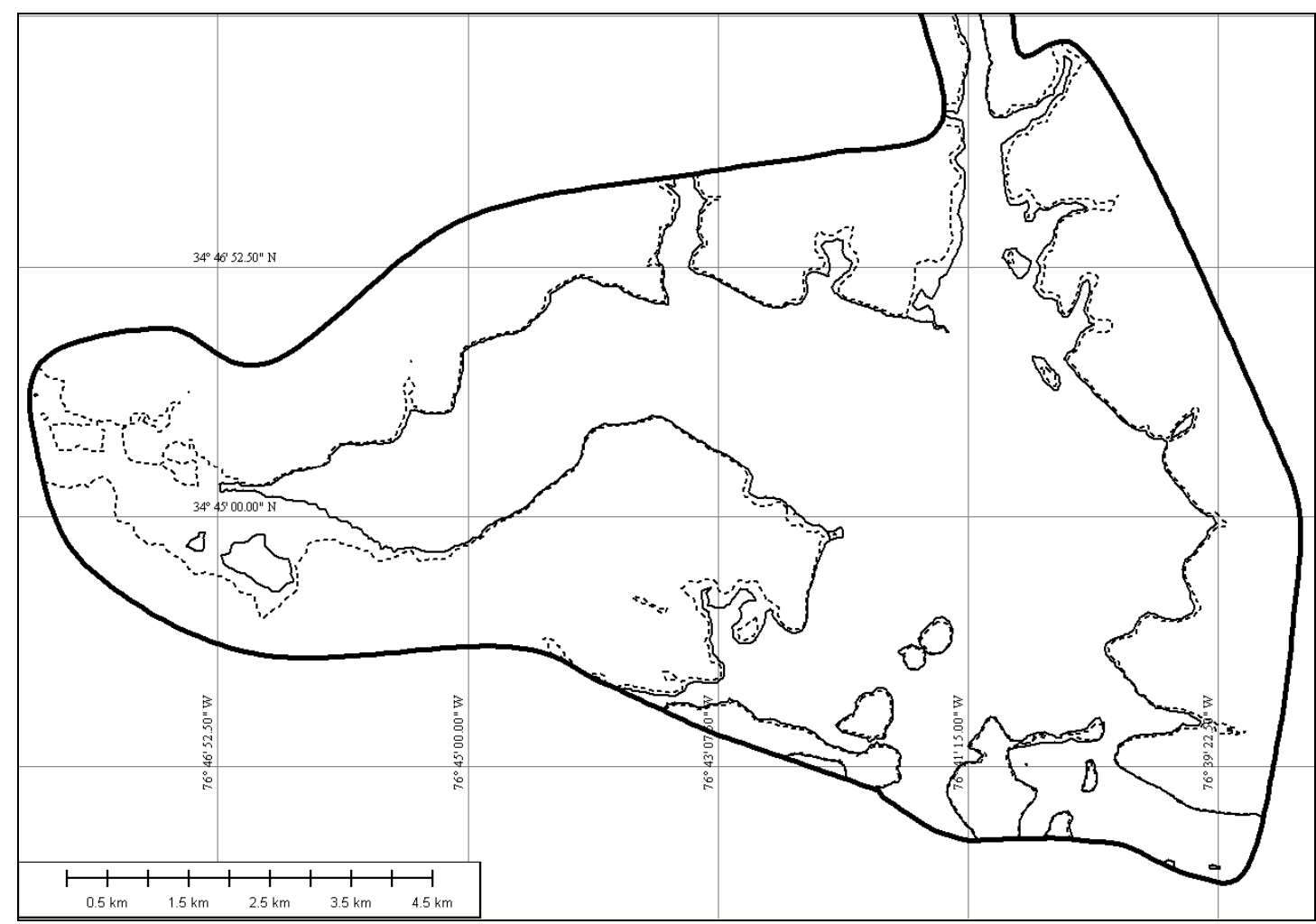

Figure 8. Computed present day (-) and 0.30 m SLR (- -) MHW shorelines for the lower Newport River with domain boundary in bold. 